Patients who are at risk of carrying a fetus with a genetic disorder should be considered in two categories - high and low risk. Those at high risk include families in which the single gene disorders are segregated or those where one parent carries a chromosome rearrangement leading to a significant risk of an unbalanced offspring. Such couples should be referred early, preferably before pregnancy, to allow carrier state to be assessed and linkage studies to be carried out when appropriate. For such women chorion villus sampling is an excellent method that allows couples at genetic disadvantage the chance to reproduce normally.

The application of chorion villus sampling for women of low genetic risk - for example, those over the age of 35 years - is questionable. Not only does there appear to be an increased risk of miscarriage related to the procedure but the woman is far more likely to need a termination of pregnancy owing to the increased number of fetuses with chromosome abnormalities in the first trimester of pregnancy, many of which would abort naturally. Women should also be warned that the incidence of false positive diagnoses is higher than with amniocentesis. ${ }^{2}$ If both direct and culture preparations of chorionic villus samples are used then many of the placental mosaics that are not reflected in the fetus can be recognised, but in most cases this still means undergoing an amniocentesis to confirm fetal chromosome state. Such diagnostic difficulties not only are costly in clinical and laboratory time but also cause enormous emotional stress and increase the risk of pregnancy loss because of the need for two invasive procedures. Women who are offered chorion villus sampling and who are at low risk should be told that there is about a $1 \%$ chance that a reassuring amniocentesis will be required. We acknowledge that our patients must reach their own decisions but it must be in full knowledge of the benefits and risks of each procedure. The recent introduction of the combination of serum $\alpha$ fetoprotein, oestriol, and human chorionic gonadotrophin as a screening test for Down's syndrome ${ }^{3}$ was overlooked in the article. This "triple test" will increase our ability to detect Downs's syndrome in women aged under 35 and will also lessen the need for amniocentesis in some women aged over 35. Again, adequate explanation is important as it is not a diagnostic test but merely changes the patient's odds of giving birth to an infant with Down's syndrome.

The question of increased maternal anxiety is also important in offering maternal serum $\alpha$ fetoprotein screening for neural tube defects. Leaving aside the vexed question of whether to screen by means of ultrasound or maternal serum $\alpha$ fetoprotein, or both, Dr Bull's paper contains some general advice on the interpretation of $\alpha$ fetoprotein screening results which suggests a lack of understanding of screening tests. The predictive value of a positive test result - that is, the chances of the patient carrying a fetus with a neural tube defect if the test is reported as abnormal-depends on the prevalence of neural tube defects in that area. Considering a test result as abnormal only if it is over 2.5 multiples of the median may therefore not be appropriate for areas of low prevalence. As the overall prevalence of neural tube defects is declining the cut off point for an abnormal test should be reconsidered regularly.

Poor understanding of the nature of screening tests is also shown in this article by the description of the use of random blood glucose testing at 28-30 weeks. Dr Bull suggests that we should screen only obese women, those who have had glycosuria, and those who have had a large baby. He further suggests that these women should be screened according to the criteria of Lind. ${ }^{4}$ Lind's test was designed to be applied to the entire pregnant population and was proposed because the standard clinical means of screening for abnormal glucose tolerance in pregnancy are so poor; it was also designed to replace urine analysis for glucose. This is an example of applying a screening test to an already screened population.

RICHARD PENKETH J MALCOLM PEARCE

Academic Department of Obstetrics,

St George's Hospital,

Leorge's Hospita,

1 Bull MJV. Screening in practice: maternal and fetal screening for antenatal care. Br Med f 1990;300:1118-20. (28 April.)

2 Leschot N, Wolf H, van Prooijen-Knegt A, et al. Cytogenetic findings in the first 1250 chorionic villus samples obtained in the first trimester with clinical follow-up of the first 1000 pregnancies. Br f Obstet Gynaecol 1989;96:663-70.

3 Wald N, Cuckle H, Densem J, et al. Maternal serum screening for Down's syndrome in early pregnancy. Br Med $\mathcal{f}$ 1988;297:883-7.

4 Lind T. Antenatal screening for diabetes mellitus. $\mathrm{Br} \mathcal{F}$ Obstet Gynaecol 1984;91:833-4.

\section{The GP contract}

SIR,-Dr R R Charlwood's letter deserves comment and should encourage more discussion in your columns than hitherto. ${ }^{1}$

I agree that there was a serious lack of local representation through local medical committees. Representatives to conferences, particularly the second special conference of representatives of local medical committees called to discuss these proposals last year, ${ }^{2}$ were unclear whether to vote individually or on instructions from their local committees. Many were inexperienced, attending their first representatives' meeting. It has been obvious since then that instructions to representatives were not forthcoming and that the views of the profession as a whole, for more active and aggressive action such as sanctions, seemed to be disregarded totally by our General Medical Services Committee. The committee's decisions and actions did not represent "grass roots" opinion and this failure was reflected in the closeness of the voting at the special representatives' meeting.

The BMA council, the members' central executive, has similar problems over representation. Of the 50 representatives voted in at the recent election, just over half were general practitioners, of whom 19 were returned unopposed-does this reflect the apathy of the members? Only about one third of those members eligible to vote for them actually did so, and of doctors in the training grades only $15 \%$ considered the elections sufficiently important to express their opinions. Apparently, one general practitioner member can represent adequately each of Wales, Northern Ireland, and Scotland on the council. Only one candidate in that election was opposed.

Election of GMSC members shows similar dilution of local representation. Vacancies are filled haphazardly - by those who crave publicity or, as was the case recently, those who represented strong anti-government political views.

Would there be better representation were the BMA to be organised and structured more on the lines of a professional trade union? Had the GMSC negotiators been full time professionals, would they have negotiated a better deal? Indeed, would the practicalities of, say, immunisation targets have been realised earlier and more skilfully negotiated to the profession's advantage? The introduction of the Industrial Relations Bill by the Conservative government in 1970 made it possible for the BMA to remain in its existing form as "an organisation of workers." After representation by the BMA it was later allowed to be entered in a special register acquiring all the privileges and responsibilities of a trade union but without any change in its constitution. The incoming Labour government repealed the act, but, later, in the Trade Union and Labour Relations Act of 1974 this right was restored.

One of the successes of the BMA in the past few years has been the growth of its network of industrial relations officers. Why was this expertise not tapped? Why was there not a negotiator with this special experience in the team? Is not a "contract" of employment an industrial relations matter? Aneurin Bevan once stated during a disarmament conference that the Labour government was so unprepared, with no alternatives to put forward, that he felt he had gone "naked into the conference table." That is what the GMSC appeared to do in its recent negotiations.

Before the last reorganisation of the NHS in 1974 the BMA appointed Sir Paul Chambers, a well known industrialist, to inquire into the association's constitution and organisation. Published in 1972, the report commented on the cumbersome nature of the organisation and the BMA's dilemma in trying to be on the one hand truly democratic and representing all opinions while on the other trying to achieve rapid professional action, particularly when faced with determined politicians. ${ }^{3}$ Chambers felt that the views of the majority should be represented by a small group of executive members. Unfortunately the report was ignored by the profession.

The BMA tell us that most doctors are now members of the association. So why should not each general practitioner have a vote in the election of one local GMSC member? Some might suggest that candidates would be unknown but many members of local medical committees do not know who their central representatives are now. Regional representatives tell us that it is impossible for them to attend both central and local committee meetings so how can they gauge local opinion accurately?

We need another special independent inquiry into the mechanics of our constitution and organisation with the aim of better direct representation of local opinion. We must not, as Dr Charlwood states, be caught out again.

E M JONES

Stockport SK8 3JD

1 Charlwood RR. The GP contract. Br Med f 1990;300:1401. (26 May.)

2 Beecham L. Contract rejected; ballot called; more talks wanted. BrMed F 1989;299:57.

3 Chambers P. Report of an inquiry into the association's constitution and organisation. $\mathrm{Br} \mathrm{Med} \mathcal{F}$ 1972;ii:45-67.

** The secretary writes: Doctors attending the BMA conferences do so as representatives and not as delegates and so may vote on proposals in the light of the debates and of up to date information available at the time, taking account of the known views of their local constituents. Doctors elected to the BMA's council and craft committees need to devote time and effort to representing their colleagues. This limits the numbers who are able to stand for election. The number of members who vote in elections to the council compares favourably with those in similar organisations. The smaller proportion of those in the training grades who vote is largely accounted for by the difficulty in keeping up to date lists of a mobile electorate.

The BMA has no special register rights as a union under the Trade Union and Labour Relations Act 1974. In negotiations the BMA uses those people it considers will be able to obtain the best deals for its members. It employs experts in industrial relations, provides training for its negotiators, and uses its industrial relations officers to provide advice to all of the BMA's negotiating groups. Experience with successive governments has also taught the BMA the value of negotiations being led by practising doctors. Sir Paul Chambers suggested radical reforms to the association's constitution and, though many were not adopted, some of his ideas were used in restructuring the association's council and committees. Subsequently, trade union legislation obliged the association to modify its election arrangements to the council, thus upsetting a balanced representation of all crafts. It is open to Dr Jones as a member to persuade his division to put an appropriate motion to the representative body proposing an inquiry on or amendments to the BMA's constitution. 